\title{
Pharmacokinetics of Intravenously Administered Levofloxacin in Men and Women
}

\author{
Brian R. Overholser, Pharm.D., Michael B. Kays, Pharm.D., FCCP, Seema Lagvankar, D.O., \\ Mitchell Goldman, M.D., Bruce A. Mueller, Pharm.D., FCCP, and Kevin M. Sowinski, Pharm.D., FCCP \\ Study Objective. To characterize and compare the pharmacokinetics of \\ levofloxacin in men and women after systemic administration. \\ Design. Prospective, open-label, parallel group pharmacokinetic study. \\ Setting. University research center. \\ Subjects. Eleven healthy men and nine healthy women stratified by body \\ mass index. \\ Intervention. Subjects received levofloxacin as a single 500-mg intravenous \\ dose. Serum and urine were collected over 36 hours. \\ Measurements and Main Results. Levofloxacin concentrations were \\ determined by high-performance liquid chromatography with ultraviolet \\ detection. Pharmacokinetic analysis was performed with ADAPT II \\ software (University of Southern California, Los Angeles, CA). Median \\ (range) body mass index was $23.2 \mathrm{~kg} / \mathrm{m}^{2}\left(19.9-28.3 \mathrm{~kg} / \mathrm{m}^{2}\right.$ ) for men and \\ $23.6 \mathrm{~kg} / \mathrm{m}^{2}\left(16.0-32.4 \mathrm{~kg} / \mathrm{m}^{2}\right)$ for women $(\mathrm{p}=0.67)$. A two-compartment \\ model best fit the pharmacokinetic data: median (range) $\mathrm{R}^{2}$ was 0.996 \\ (0.990-0.999). Women had a $24 \%$ greater exposure to levofloxacin, with a \\ significantly smaller steady-state volume of distribution $(\mathrm{p}<0.01)$ and a \\ slower clearance $(\mathrm{p}<0.01)$. \\ Conclusions. Differences exist in the disposition of levofloxacin between \\ healthy men and women after systemic administration. Fixed intravenous \\ doses of levofloxacin will lead to greater drug exposure in women. Thus, \\ women may have more of an increased risk of fluoroquinolone toxicity \\ than men, and men may need higher doses to achieve similar drug efficacy \\ than women. Levofloxacin dosage adjustments based on sex should be \\ considered on an individual basis.
}

Key Words: levofloxacin, pharmacokinetics, sex-based differences.

(Pharmacotherapy 2005;25(10):1310-1318)

Fluoroquinolones are broad-spectrum antibiotics commonly used in the treatment of community-acquired pneumonia, among several other infections. They are generally well tolerated, although central nervous system and gastrointestinal adverse effects are common., ${ }^{1,2}$ Observational data suggest that women may have a greater frequency of these adverse effects with certain fluoroquinolone antibiotics than do men. ${ }^{3,4}$ This increased toxicity in women may be attributed to an underlying disposition or response difference to fluoroquinolones between the sexes.

Previous reports indicate that women have increased maximum serum concentrations $\left(\mathrm{C}_{\max }\right)$ and a greater exposure to several fluoroquinolones. ${ }^{5-10}$ In most of these studies, the estimated volume of distribution of the compound of interest was found to be smaller in women compared with that in men but was attenuated when normalized to body weight. Other studies report an absence of a sex-related effect on fluoroquinolone disposition when pharmacokinetic parameters are normalized to 
total body weight, although none of the studies reported pharmacokinetic parameters unadjusted for weight. ${ }^{2,11,12}$ Thus, available data suggest that because of smaller body weights, women may be exposed to higher plasma fluoroquinolone concentrations than are men when equal doses are administered. Despite body composition differences, however, to our knowledge, relationships between fluoroquinolone pharmacokinetics and total body weight have not been investigated in men and women to justify weight normalization of pharmacokinetic parameters between the sexes.

We previously published the sex-related effects on the pharmacokinetics of ofloxacin administered as a single 400-mg oral dose in male and female volunteers. ${ }^{10}$ Consistent with previous fluoroquinolone studies, the apparent steady-state volume of distribution $\left(\mathrm{V}_{\mathrm{ss}}\right)$ was significantly lower in women than in men, and after weight adjustment the difference was attenuated and no longer statistically significant. Of particular interest, data from that study suggest that differences may exist in the relationship between the apparent $\mathrm{V}_{\mathrm{ss}}$ of ofloxacin and total body weight in men and women. In men, a strong positive relationship between total body weight and the apparent $\mathrm{V}_{\mathrm{ss}}$ was observed. In the women, however, no apparent relationship was noted between $\mathrm{V}_{\mathrm{ss}}$ and total body weight. If a

From the Department of Pharmacy Practice, Purdue University School of Pharmacy and Pharmaceutical Sciences, Indianapolis and West Lafayette, Indiana (Drs. Overholser, Kays, and Sowinski); the Department of Medicine, Indiana University School of Medicine, Indianapolis, Indiana (Drs. Overholser, Kays, Lagvankar, Goldman, and Sowinski); and the Department of Clinical Sciences, University of Michigan College of Pharmacy, Ann Arbor, Michigan (Dr. Mueller).

Supported in part by grants from the Purdue Research Foundation, West Lafayette, Indiana, and by a grant (M01 RR00750) from the National Institutes of Health, Bethesda, Maryland. Dr. Overholser's fellowship was funded in part by the American College of Clinical Pharmacy Research Institute-Aventis Pharmaceuticals Infectious Diseases Research Fellowship, Kansas City, Missouri, and the American Foundation for Pharmaceutical Education, Rockville, Maryland.

Presented in part at the annual meeting of the American College of Clinical Pharmacy, Atlanta, Georgia, November 2-5, 2003, and the annual meeting of the American Society for Clinical Pharmacology and Therapeutics, Miami, Florida, March 24-27, 2004.

Manuscript received January 3, 2005. Accepted pending revisions March 21, 2005. Accepted for publication in final form June 22, 2005.

Address reprint requests to Kevin M. Sowinski, Pharm.D., Purdue University, Department of Pharmacy Practice, W7555 Myers Building, WHS, 1001 West 10th Street, Indianapolis, IN 46202; e-mail: ksowinsk@iupui.edu. distinct relationship exists between the sexes, pharmacokinetic parameter normalization to total body weight may be inappropriate for ofloxacin. Since that study was performed after administration of an oral dose, differences in the clearance and $\mathrm{V}_{\text {ss }}$ could not be distinguished from potential differences in oral bioavailability.

Levofloxacin, the pharmacologically active Senantiomer of racemic ofloxacin, is frequently used in clinical practice, but potential sex-based disposition differences after intravenous administration have not been established. ${ }^{2}$ Based on observations from the ofloxacin study, we hypothesized that sex-based differences exist in the pharmacokinetics of levofloxacin after systemic administration. Therefore, we sought to investigate the pharmacokinetics of intravenous levofloxacin in a group of men and women stratified by body mass index. An additional aim was to justify a weight-based normalization of pharmacokinetic parameter estimates by assessing the relationships between body weight and composition with systemic clearance $\left(\mathrm{Cl}_{\mathrm{s}}\right)$ and apparent $\mathrm{V}_{\mathrm{ss}}$ in men and women.

\section{Methods}

\section{Study Subjects}

Men were enrolled without restriction into one of three groups stratified by body mass index: less than $20 \mathrm{~kg} / \mathrm{m}^{2}, 20-25 \mathrm{~kg} / \mathrm{m}^{2}$, and greater than $25 \mathrm{~kg} / \mathrm{m}^{2}$. Women were matched to the men based on the stratified groups to ensure similar numbers of men and women in each group. The stratification procedure was implemented to ensure similar body mass indexes were observed between male and female study subjects at study completion. Healthy, nonsmoking male and female volunteers aged 18-40 years were recruited for study participation.

An initial interview was conducted to ascertain information regarding the subject's medical history, current use of drugs, and history of allergies. Subjects were excluded if they were taking any drugs, including over-the-counter drugs within 24 hours before the study visit. Premenopausal women with a history of a regular menstrual cycle and not using any hormonecontaining contraceptive methods were eligible for study participation. Women were instructed to use abstinence or effective barrier contraceptive methods from the initial screening until a minimum of 1 week after the study period. Two urine pregnancy tests were obtained for each woman, one during screening and one before 
drug administration. Subjects were excluded from participating in the study if they were allergic to fluoroquinolone antibiotics or heparin or if women were breast-feeding, pregnant, or intending to become pregnant within 30 days of the study period. All subjects underwent a screening evaluation based on medical history, physical examination, routine serum chemistry, and urinalysis. Clinically significant abnormalities in any of these tests were criteria for exclusion from study participation.

All subjects provided written informed consent before enrollment, and the study was approved by the Institutional Review Board at Indiana University-Purdue University Indianapolis, Indianapolis, Indiana.

\section{Size Descriptors}

Male and female volunteers were stratified by an estimated body mass index (BMI $\left[\mathrm{kg} / \mathrm{m}^{2}\right]$ ) calculation (Equation 1). ${ }^{13}$ In addition, ideal body weight (IBW $[\mathrm{kg}]$ ), lean body weight (LBW $[\mathrm{kg}]$ ), and body surface area (BSA $\left[\mathrm{m}^{2}\right]$ ) were estimated for all study subjects by using Equations 2-4. ${ }^{14-16}$ Weight is in kilograms and height is in meters, unless otherwise indicated.

(Eq. 1) $\mathrm{BMI}=$ weight $/$ height $^{2}$

(Eq. 2) $\mathrm{IBW}_{\text {men }}=50+2.3$ (height -60$)$, and $\mathrm{IBW}_{\text {women }}=45.5+2.3$ (height -60$)$, where height is in inches

(Eq. 3) $\mathrm{LBW}_{\text {men }}=(1.10 \cdot$ weight $)-$ $128\left[\right.$ weight $^{2} /(100 \bullet \text { height })^{2}$ ] $\mathrm{LBW}_{\text {women }}=(1.07 \cdot$ weight $)-$ $148\left[\right.$ weight $\left.^{2} /(100 \cdot \text { height })^{2}\right]$

(Eq. 4) BSA = weight ${ }^{0.425} \bullet$ height $^{0.725} \bullet 0.20247$

\section{Study Protocol}

Subjects were instructed to avoid alcohol, caffeine, fruit, and fruit juices 24 hours before and during the entire study period. On the morning of the study, after an 8-hour fast, subjects reported to the Indiana University General Clinical Research Center (GCRC), where on arrival a venous catheter was inserted into a forearm vein of each arm. Each subject received levofloxacin (Levaquin; Ortho-McNeil Pharmaceutical, Inc., South Raritan, NJ) as a single 500-mg dose administered with an intravenous infusion pump over 60 minutes. Subjects continued to fast for an additional 4 hours after the end of the infusion. Venous blood samples $(10 \mathrm{ml})$ were obtained from the indwelling catheter contralateral to the infusion arm, into evacuated blood collection tubes that contained no anticoagulant, immediately before and at $0,0.25,0.5,1,2,3,4,6,8,12,18,24$, and 36 hours after the infusion. The venous catheter was removed at 24 hours, and blood samples obtained at 36 hours after the infusion were obtained by a separate venipuncture. Blood was allowed to clot; serum was separated by centrifugation and stored at $-70^{\circ} \mathrm{C}$ until analysis. Subjects were instructed to void before drug administration, and urine was collected for the entire 36-hour study period: between 0 and 24 hours in the GCRC and between 24 and 36 hours as an outpatient. The volume was determined, and an aliquot was stored at $-70^{\circ} \mathrm{C}$ until analysis.

Sample Analysis

Levofloxacin concentrations in serum and urine were determined by a modified reversephase high-performance liquid chromatography method with ultraviolet detection, as previously described for the quantification of levofloxacin in serum. ${ }^{17}$ Serum samples were thawed at room temperature and vortexed for 30 seconds, and a $50-\mu \mathrm{l}$ aliquot was collected. After addition of a displacing reagent (acetonitrile-water [20:80, volume:volume ratio, v:v] containing $0.5 \%$ sodium dodecyl sulfate [SDS] and $0.075 \mathrm{~mol} / \mathrm{L}$ phosphate) containing the internal standard (ciprofloxacin; Bayer, West Haven, CT), serum samples were ultrafiltered with an Amicon Centrifree apparatus (Amicon Division, W.R. Grace \& Co., Beverly, MA). The ultrafiltrates were then injected onto an Adsorbosphere HS $\mathrm{C}_{18}$ column (particle size $5 \mu \mathrm{m}, 4.6 \times 250 \mathrm{~mm}$; Alltech Associates, Deerfield, IL) with ultraviolet detection $(280 \mathrm{~nm})$. The mobile phase consisted of acetonitrile-water (40:60 v:v) containing 0.01 $\mathrm{mol} / \mathrm{L}$ SDS, $0.01 \mathrm{~mol} / \mathrm{L}$ tetrabutylammonium acetate, and $0.025 \mathrm{~mol} / \mathrm{L}$ citric acid. The serum standard curves were linear over the calibration range of $0.1-10 \mathrm{mg} / \mathrm{L}$ with a lower limit of detection of $0.375 \mathrm{mg} / \mathrm{L}$. Serum samples greater than $10 \mathrm{mg} / \mathrm{L}$ were diluted 2-fold and reanalyzed. At quality control serum concentrations of 0.375 , 1.50 , and $6.00 \mathrm{mg} / \mathrm{L}$, interday and intraday coefficients of variation were $7 \%$ or less.

The equipment and conditions for the urine levofloxacin assay were identical to those described for the serum assay. Urine samples were thawed and vortexed for 30 seconds, and a $50-\mu l$ aliquot was diluted with $1000 \mu$ of mobile phase. Fifty microliters of internal standard 
(ciprofloxacin $30 \mu \mathrm{g} / \mathrm{ml}$ ) were added to the diluted sample and vortexed for an additional 30 seconds before being transferred to a vial and directly injected onto the column for analysis. The urine calibration curve was linear from $1-500 \mathrm{mg} / \mathrm{L}$ with a lower limit of detection of $3.75 \mathrm{mg} / \mathrm{L}$. At urine quality control concentrations of $3.75,37.5$, and $375 \mathrm{mg} / \mathrm{L}$, interday and intraday coefficients of variation were $12 \%$ and $9 \%$ or less, respectively.

Serum and urine creatinine concentrations were determined by a colorimetric method using a COBAS-Mira spectrophotometer (Roche, Basel, Switzerland) in the Indiana University GCRC core analytical laboratory. Interday and intraday coefficients of variation were $5 \%$ or less. The 24 hour creatinine clearance $\left(\mathrm{Cl}_{\mathrm{cr}}\right)$ values were calculated from the urine collection by standard methods.

\section{Pharmacokinetic Analysis}

Pharmacokinetic parameters were estimated by fitting pharmacokinetic models to the levofloxacin serum concentration-time data by using maximum likelihood estimation in ADAPT II, release $4 .{ }^{18}$ The variance model assumed that the standard deviation of the residuals was linear with increasing concentrations using Equation 5:

(Eq. 5)

$$
f(\mathrm{~V})=\left[\mathrm{y}_{\text {int }}+\mathrm{m}(\mathrm{y})\right]^{2}
$$

where $y_{\text {int }}$ is the $y$ intercept of the residual plot and $\mathrm{m}$ is the slope of the line. The y intercept was initially fixed at one half of the lower limit of detection for the levofloxacin serum assay and estimated with the combined residuals from all subjects from the final two-compartment model. The slopes were initially set at $10 \%$ and estimated in each individual subject.

Model discrimination was accomplished by visual inspection of the distribution of the weighted residuals, Akaike information criteria, ${ }^{19}$ sums of the squared weighted residuals, and visual inspection of the predicted versus measured data. The pharmacokinetic model that was best fit to the serum concentration-time data was a two-compartment model with first-order elimination from the central compartment. The model was parameterized by using apparent volume of distribution of the central compartment $\left(\mathrm{V}_{\mathrm{c}}\right)$, apparent volume of distribution of the peripheral compartment $\left(\mathrm{V}_{\mathrm{p}}\right), \mathrm{Cl}_{\mathrm{s}}$, and distribution clearance between the central and peripheral compartments $\left(\mathrm{Cl}_{\mathrm{d}}\right)$.

Secondary pharmacokinetic parameters derived from model estimates including terminal elimination half-life $\left(\mathrm{t}_{1 / 2}\right)$ were calculated by standard methods. ${ }^{20}$ Apparent $\mathrm{V}_{\mathrm{ss}}$ and renal clearance $\left(\mathrm{Cl}_{\mathrm{r}}\right)$ were calculated with Equations 6 and 7 , respectively:

$$
\begin{array}{ll}
\text { (Eq. 6) } & \mathrm{V}_{\mathrm{ss}}=\mathrm{V}_{\mathrm{c}}+\mathrm{V}_{\mathrm{p}} \\
\text { (Eq. 7) } & \mathrm{Cl}_{\mathrm{r}}=\mathrm{Ae}_{0-36} / \mathrm{AUC}_{0-36}
\end{array}
$$

where $\mathrm{Ae}_{0-36}$ is the amount of levofloxacin excreted in the urine from 0-36 hours after administration and $\mathrm{AUC}_{0-36}$ is the area under the concentration-time curve from $0-36$ hours. The area under the levofloxacin concentration-time curve from time zero to infinity $\left(\mathrm{AUC}_{0-\infty}\right)$ and $\mathrm{AUC}_{0-36}$ were calculated by the integration of the model-derived concentration-time curves. The levofloxacin $\mathrm{C}_{\max }$ was obtained by visual inspection of each subject's model-derived concentration-time profile.

\section{Statistical Analysis}

Statistical analyses were performed by using SigmaStat for Windows, version 2.03 (SPSS Inc., Chicago, IL). Statistical comparisons of pharmacokinetic parameter estimates between men and women were performed with the Wilcoxon rank sum test. Univariate least squares linear regression was used to examine the relationship between $\mathrm{Cl}_{\mathrm{s}}$ and $\mathrm{V}_{\mathrm{ss}}$ of levofloxacin with $\mathrm{Cl}_{\mathrm{cr}}$, body mass index, ideal body weight, lean body weight, body surface area, and total body weight in men and women. Overall differences were considered statistically significant at a $\mathrm{p}$ value less than 0.05 .

\section{Results}

The study group was composed of 20 healthy volunteers: 11 men aged 19-39 years (median 27 yrs) and 9 women aged 19-37 years (median 31 yrs). All 20 participants successfully completed the study without any clinically significant adverse effects and were included in the data analysis. Eight subjects were selfreported Caucasian (six men, two women), three African-American (two men, one woman), seven Asian (two men, five women), and two Hispanic (one man, one woman). Individual body mass indexes and total body weights in men and women are depicted in Figure 1. Subject demographics including body surface area, ideal body weight, and lean body weight in the study groups are displayed in Table 1. The mean \pm SD 24-hour $\mathrm{Cl}_{\mathrm{cr}}$ values for men and women were 
Table 1. Demographics of the Study Subjects

\begin{tabular}{lccc}
\hline & $\begin{array}{c}\text { Men } \\
(\mathrm{n}=11)\end{array}$ & $\begin{array}{c}\text { Women } \\
(\mathrm{n}=9)\end{array}$ & p Value \\
\hline Body mass index $\left(\mathrm{kg} / \mathrm{m}^{2}\right)$ & $23.2(19.9-28.3)$ & $23.6(16.0-32.4)$ & 0.67 \\
Total body weight $(\mathrm{kg})$ & $74.8(57.1-92.3)$ & $64.1(51.2-79.9)$ & 0.03 \\
Height $(\mathrm{cm})$ & $177(154-198)$ & $168(157-180)$ & 0.03 \\
Body surface area $\left(\mathrm{m}^{2}\right)$ & $1.93(1.54-2.24)$ & $1.67(1.53-1.85)$ & 0.02 \\
Ideal body weight $(\mathrm{kg})$ & $72.0(51.0-91.0)$ & $60.0(50.0-70.0)$ & $<0.01$ \\
Lean body weight $(\mathrm{kg})$ & $60.0(45.0-72.0)$ & $45.0(40.0-51.0)$ & $<0.01$ \\
\hline
\end{tabular}

Data are median (range).

$105.7 \pm 33.6$ and $97.0 \pm 37.5 \mathrm{ml} / \mathrm{minute}$, respectively $(\mathrm{p}=0.59)$.

The final pharmacokinetic model fit to the data was a two-compartment open model with firstorder elimination from the central compartment. The median (range) $\mathrm{R}^{2}$ for individual fits with the final model was 0.996 (0.990-0.999). Levofloxacin serum concentration versus time data obtained from a representative male subject and female subject with the fitted serum concentration-time curve are shown in Figure 2. The representative subjects had similar estimated pharmacokinetic parameters to those of the medians obtained from each study group.

Model-estimated pharmacokinetic parameters after intravenous levofloxacin administration are presented in Table 2. The $\mathrm{Cl}_{\mathrm{s}}$ of levofloxacin was significantly $(\mathrm{p}<0.01)$ slower in women compared with that in men. Similarly, women had a $40 \%$ slower $\mathrm{Cl}_{\mathrm{r}}$ of levofloxacin despite a comparable $(\mathrm{p}=0.61)$ 24-hour $\mathrm{Cl}_{\mathrm{cr}}$. The nonrenal clearance (i.e., $\mathrm{Cl}_{\mathrm{s}}-\mathrm{Cl}_{\mathrm{r}}$ ) was not significantly different between men and women of this study $\left(\mathrm{p}=0.72\right.$, data not shown). The $\mathrm{V}_{\mathrm{ss}}$ and $\mathrm{V}_{\mathrm{c}}$ of
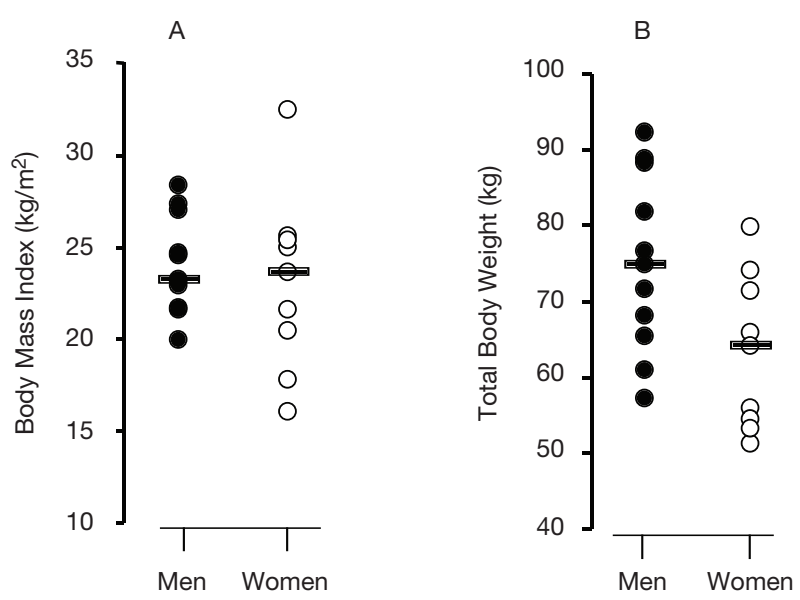

Figure 1. Body mass index (A) and total body weight (B) of the study participants. The medians are identified by $(-)$. levofloxacin were significantly $(\mathrm{p}<0.01)$ smaller in women, in concert with a significant $25 \%$ increase in the median levofloxacin $C_{\max }$. Women had a $24 \%$ increase in the total exposure to levofloxacin as determined by a significantly larger $\mathrm{AUC}_{0-\infty}$. The $\mathrm{Cl}_{\mathrm{d}}$ and $\mathrm{t}_{1 / 2}$ for levofloxacin were not significantly different between sexes ( $\mathrm{p}=0.56$ and 0.06 , respectively).

The individual pharmacokinetic parameter estimates were used to simulate the predicted steady-state levofloxacin serum concentrations in each subject. The mean \pm SD steady-state levofloxacin concentrations were estimated by the predicted steady-state concentrations in men and women separately. Figure 3 displays the mean \pm SD predicted steady-state levofloxacin concentrations after a 5-day regimen of intravenous levofloxacin $500 \mathrm{mg}$ administered by a 60-minute infusion every 24 hours.

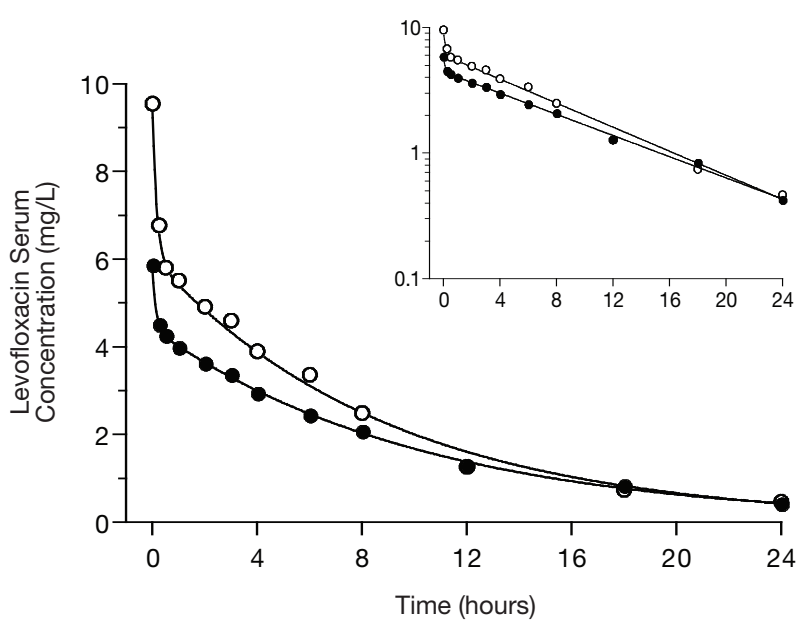

Figure 2. Levofloxacin concentration-time profiles after a 60-minute intravenous infusion of levofloxacin $500 \mathrm{mg}$, in a representative male (O) and female $(\bigcirc)$ subject. Symbols represent observed concentration values, with a fitted line depicting the serum levofloxacin concentrations predicted from the pharmacokinetic model. Insert displays the concentration-time curve on a log-linear scale. 
Table 2. Pharmacokinetic Parameter Estimates for Levofloxacin in Men and Women

\begin{tabular}{lccc}
\hline Parameter & $\begin{array}{c}\text { Men } \\
(\mathrm{n}=11)\end{array}$ & $\begin{array}{c}\text { Women } \\
(\mathrm{n}=9)\end{array}$ & $\mathrm{p}$ Value \\
\hline $\mathrm{Cl}_{\mathrm{s}}(\mathrm{L} / \mathrm{hr})$ & $11.0(9.33-16.5)$ & $8.87(7.90-10.7)$ & $<0.01$ \\
$\mathrm{Cl}_{\mathrm{r}}(\mathrm{L} / \mathrm{hr})$ & $10.4(7.65-13.5)$ & $6.31(4.52-9.33)$ & $<0.01$ \\
$\mathrm{~V}_{\mathrm{c}}(\mathrm{L})$ & $58.4(25.5-84.7)$ & $22.0(7.34-74.6)$ & $<0.01$ \\
$\mathrm{~V}_{\mathrm{ss}}(\mathrm{L})$ & $117(93.3-152)$ & $81.0(59.7-105)$ & $<0.01$ \\
$\mathrm{Cl}_{\mathrm{d}}(\mathrm{L} / \mathrm{hr})$ & $73.9(7.57-560)$ & $75.5(1.99-399)$ & 0.56 \\
$\mathrm{t}_{1 / 2}(\mathrm{hr})$ & $7.3(6.4-9.4)$ & $6.4(5.4-13)$ & 0.06 \\
$\mathrm{C}_{\max }(\mathrm{mg} / \mathrm{L})$ & $5.4(4.7-6.2)$ & $6.7(5.9-13)$ & $<0.01$ \\
$\mathrm{AUC} C_{0-\infty}(\mathrm{mg} \bullet \mathrm{hr} / \mathrm{L})$ & $45.5(30.3-53.6)$ & $56.4(46.8-63.3)$ & $<0.01$ \\
\hline
\end{tabular}

Data are median (range).

$\mathrm{Cl}_{\mathrm{S}}=$ systemic clearance $; \mathrm{Cl}_{\mathrm{r}}=$ renal clearance; $\mathrm{V}_{\mathrm{C}}=$ central compartment volume of distribution; $\mathrm{V}_{\mathrm{SS}}$ = steady-state volume of distribution; $\mathrm{Cl}_{\mathrm{d}}=$ intercompartmental distribution clearance; $\mathrm{t}_{1 / 2}=$ terminal elimination half-life; $\mathrm{C}_{\max }=$ maximum serum concentration; $\mathrm{AUC}_{0-\infty}=$ area under the concentrationtime curve from time zero to infinity.

Table 3. Body Weight-Adjusted Pharmacokinetic Parameter Estimates for Levofloxacin

\begin{tabular}{lccr}
\hline Parameter & $\begin{array}{c}\text { Men } \\
(\mathrm{n}=11)\end{array}$ & $\begin{array}{c}\text { Women } \\
(\mathrm{n}=9)\end{array}$ & $\mathrm{p}$ Value \\
\hline $\begin{array}{l}\text { Normalized for } \\
\text { total body weight }\end{array}$ & & & \\
$\mathrm{Cl}_{\mathrm{s}}(\mathrm{L} / \mathrm{hr} / \mathrm{kg})$ & $0.16(0.12-0.19)$ & $0.15(0.10-0.17)$ & 0.36 \\
$\mathrm{~V}_{\mathrm{ss}}(\mathrm{L} / \mathrm{kg})$ & $1.62(1.33-1.72)$ & $1.31(1.01-1.47)$ & $<0.01$ \\
$\begin{array}{l}\text { Normalized for } \\
\text { lean body weight }\end{array}$ & & & \\
$\mathrm{Cl}_{\mathrm{s}}(\mathrm{L} / \mathrm{hr} / \mathrm{kg})$ & $0.20(0.16-0.24)$ & $0.20(0.17-0.21)$ & 0.88 \\
$\mathrm{~V}_{\mathrm{sS}}(\mathrm{L} / \mathrm{kg})$ & $2.00(1.75-2.20)$ & $1.74(1.39-2.10)$ & $<0.01$ \\
\hline
\end{tabular}

Data are median (range).

$\mathrm{Cl}_{\mathrm{S}}=$ systemic clearance; $\mathrm{V}_{\mathrm{ss}}=$ steady-state volume of distribution .

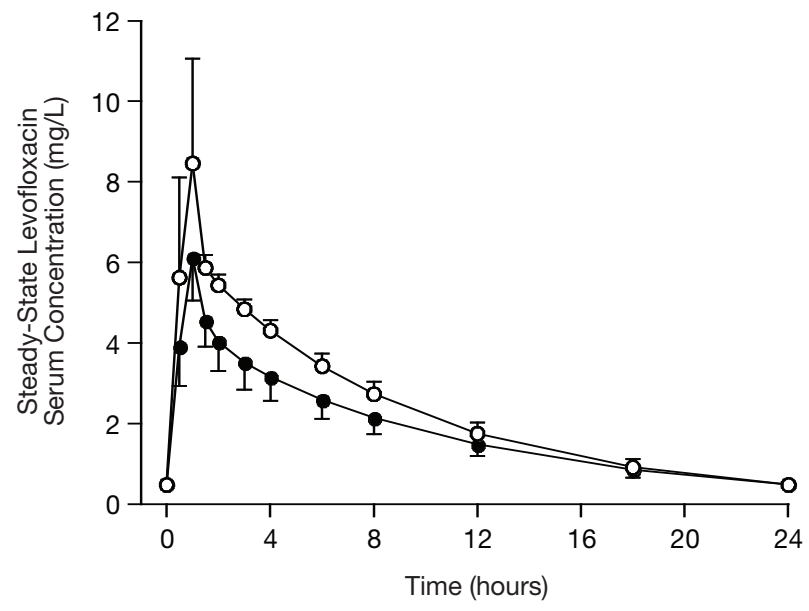

Figure 3. Predicted mean \pm SD steady-state serum levofloxacin concentration versus time curve generated from individual simulations of the pharmacokinetic parameter estimates in all study subjects. The symbols represent the predicted mean \pm SD levofloxacin serum concentrations in men (O) and women $(\bigcirc)$ at the predetermined blood sampling times, with a smooth curve though each of the mean values.
The univariate linear regression analysis revealed a positive relationship between total body weight and $\mathrm{V}_{\text {ss }}$ of levofloxacin in the combined sexes $\left(R^{2}=0.67,20\right.$ subjects, $\left.p<0.05\right)$, in men $\left(\mathrm{R}^{2}=0.79,11\right.$ subjects, $\left.\mathrm{p}<0.05\right)$, and in women $\left(\mathrm{R}^{2}=0.46,9\right.$ subjects, $\left.\mathrm{p}<0.05\right)$ alone. Figure $4 \mathrm{~A}$ shows the relationship between $\mathrm{V}_{\mathrm{ss}}$ and total body weight in men and women, separately. For any given body weight of men in this study, women of the same weight had a smaller $\mathrm{V}_{\mathrm{ss}}$ for levofloxacin. Furthermore, the univariate regression analyses of $\mathrm{V}_{\mathrm{ss}}$ displayed positive relationships versus body mass index (men $\mathrm{R}^{2}=0.18$, women $\mathrm{R}^{2}=0.31$ ), lean body weight (men $\mathrm{R}^{2}=0.77$, women $\mathrm{R}^{2}=0.55$ ), body surface area (men $R^{2}=0.77$, women $R^{2}=0.42$ ), and ideal body weight (men $\mathrm{R}^{2}=0.52$, women $\mathrm{R}^{2}=0.06$ ). Lean body weight had the strongest relationship with $\mathrm{V}_{\mathrm{ss}}$ in men, women, and the combined sexes $\left(\mathrm{R}^{2}=0.87,20\right.$ subjects, $\mathrm{p}<0.05$; Figure 4B). 
Systemic clearance and total body weight also displayed a positive relationship in the combined sexes $\left(R^{2}=0.53,20\right.$ subjects, $\left.p<0.01\right)$. However, as depicted in Figure $4 \mathrm{C}$, differences in total body weight accounted for only 19\% of the total variation of the $\mathrm{Cl}_{\mathrm{s}}$ in women and $52 \%$ in men. The $\mathrm{Cl}_{\mathrm{s}}$ of levofloxacin also displayed a positive relationship with measures of body mass index (men $\mathrm{R}^{2}=0.23$, women $\mathrm{R}^{2}=0.04$ ), lean body weight (men $\mathrm{R}^{2}=0.44$, women $\mathrm{R}^{2}=0.61$ ), body surface area (men $R^{2}=0.42$, women $R^{2}=0.40$ ), and ideal body weight (men $\mathrm{R}^{2}=0.20$, women $\left.\mathrm{R}^{2}=0.05\right)$. As seen with the relationship with $\mathrm{V}_{\mathrm{sS}}$, lean body weight had the strongest relationship with $\mathrm{Cl}_{\mathrm{s}}$ in men, women, and the combined sexes $\left(R^{2}=0.66,20\right.$ subjects, $p<0.05$; Figure 4D).

Primary pharmacokinetic parameter estimates were normalized to total body weight and lean body weight, which displayed the strongest relationship with both $\mathrm{Cl}_{\mathrm{s}}$ and $\mathrm{V}_{\text {ss }}$. Table 3 displays the lean and total body weight-adjusted $\mathrm{Cl}_{\mathrm{s}}$ and $\mathrm{V}_{\mathrm{ss}}$ for men and women. Sex-based differences in levofloxacin $\mathrm{Cl}_{\mathrm{S}}$ and $\mathrm{Cl}_{\mathrm{r}}$ were attenuated and no longer statistically significant when adjusted for total body weight $(\mathrm{p}=0.36$ and 0.50 , respectively) or lean body weight $(\mathrm{p}=0.88$ and 0.91 , respectively). However, $\mathrm{V}_{\mathrm{ss}}$ normalized to lean or total body weight remained significantly smaller $(\mathrm{p}<0.01)$ in women compared with that in men, suggesting that sexbased differences in $V_{\text {ss }}$ may exist.

\section{Discussion}

Before this investigation, to our knowledge, the sex-based pharmacokinetics of levofloxacin after intravenous administration had not been characterized. In this study, we examined the disposition of systemically administered levofloxacin in a population of men and women who were stratified by body mass index. Results
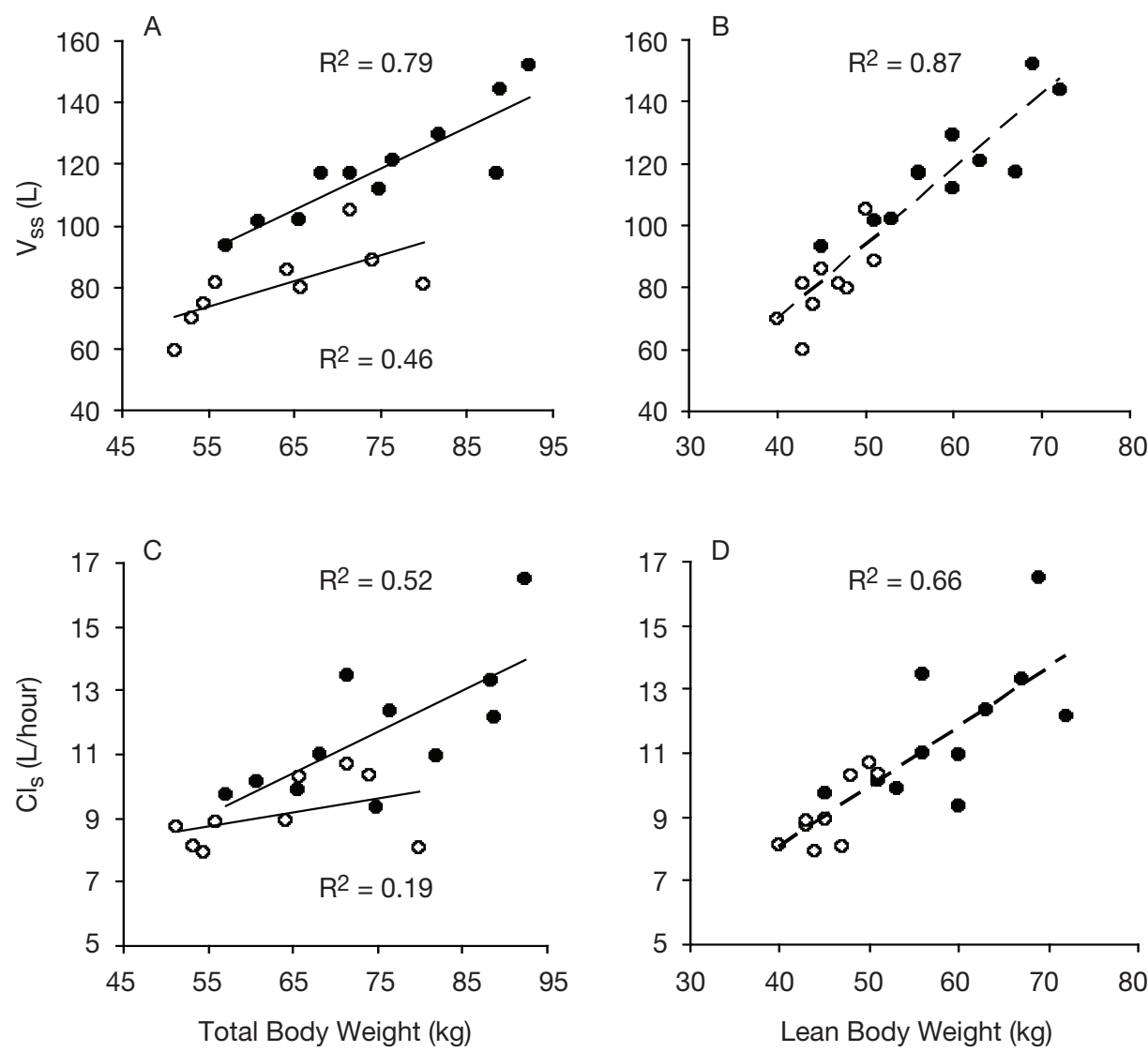

Figure 4. Relationship between levofloxacin steady-state volume of distribution $\left(\mathrm{V}_{\mathrm{ss}}\right)$ and total body weight (A), and $\mathrm{V}_{\mathrm{ss}}$ and lean body weight $(\mathrm{B})$ in men $(\mathbf{)})$ and women $(\mathrm{O})$. Relationship between levofloxacin systemic clearance $\left(\mathrm{Cl}_{\mathrm{s}}\right)$ and total body weight $(\mathrm{C})$, and $\mathrm{Cl}_{\mathrm{s}}$ and lean body weight (D) in men and women. Solid lines represent the univariate linear regression least squares fit for men and women separately and dashed lines represent the linear regression analyses for the combined study groups, with the corresponding coefficients of determination. 
indicated that, after intravenous administration, levofloxacin $\mathrm{C}_{\max }$ is considerably higher in women than in men of a similar body mass index. In addition, women displayed a greater exposure to levofloxacin due to a slower $\mathrm{Cl}_{s}$ which corresponded to a median $\mathrm{AUC}_{0-\infty}$ that was $24 \%$ higher than that of men.

The significantly slower $\mathrm{Cl}_{\mathrm{s}}$ of levofloxacin in women can predominantly be attributed to a slower $\mathrm{Cl}_{\mathrm{r}}$ of similar magnitude. However, the 24-hour $\mathrm{Cl}_{\mathrm{cr}}$ was not statistically significantly different between men and women in this study. In addition, $\mathrm{Cl}_{\mathrm{cr}}$ was not a strong predictor of the $\mathrm{Cl}_{\mathrm{r}}$ of levofloxacin $\left(\mathrm{R}^{2}=0.17\right.$, data not shown). Therefore, it is likely that the disparities in $\mathrm{Cl}_{\mathrm{r}}$ are due to differences in the tubular secretion and/or reabsorption of levofloxacin between the sexes, since it is not highly protein bound. Potential differences in tubular secretion and reabsorption have not been well studied between the sexes despite reports that suggest differing renal handling of certain drugs between men and women. ${ }^{21}$ Levofloxacin, however, has been shown to be a substrate for drug transporters in vitro, which have known activity in renal tubules. ${ }^{22}$ There is no evidence of sex-related differences in active transport proteins such as the multidrug-resistant-associated protein or the organic anion transporters in humans, but differences have been reported in animal models and may have contributed to the findings of this study. ${ }^{23}$

The higher levofloxacin $C_{\max }$ observed in women can be attributed to a significantly smaller median $\mathrm{V}_{\mathrm{c}}$. Specifically, the pharmacokinetic analysis revealed that women have both smaller $V_{c}$ and $V_{s s}$ of levofloxacin, despite an average body mass index similar to that of the male study group. On average, women did weigh less than the men in this investigation, regardless of similar body mass indexes. Nonetheless, the total body weight-adjusted $\mathrm{V}_{\mathrm{ss}}$ was significantly smaller $(\mathrm{p}<0.01)$ in women. However, the $\mathrm{V}_{\mathrm{ss}}$ normalized to total body weight should be cautiously interpreted since a distinct relationship between $\mathrm{V}_{\text {ss }}$ and total body weight was observed in men versus women (Figure 4A). Total body weight, therefore, was not found to be the best size descriptor for normalization of levofloxacin $V_{\text {ss }}$ between the sexes. Furthermore, normalization of levofloxacin $\mathrm{V}_{\mathrm{ss}}$ to total body weight may have biased the conclusions of previous pharmacokinetic investigations of levofloxacin. ${ }^{2,24}$

The estimate of lean body weight was the strongest predictor of $\mathrm{V}_{\mathrm{ss}}$ in men and women combined. Furthermore, a similar relationship between lean body weight and $V_{\text {ss }}$ was observed in men and women separately. Lean body weight differs from ideal body weight and is an estimation of bone, organ, and muscle tissue mass. Theoretically, ideal body weight can approach but never reach lean body weight in any given individual. It is not surprising that lean body weight was found to be a strong predictor of $\mathrm{V}_{\mathrm{ss}}$ in men, women, and the combined sexes since fluoroquinolones distribute more rapidly and to a greater extent into lean muscle as opposed to adipose tissue., 25-28 In fact, this property may in part explain the smaller $\mathrm{V}_{\mathrm{c}}$ and subsequent larger $C_{\max }$ after levofloxacin administration in women compared with these parameters in men. Men on average have an increased amount of body water and an increased muscle mass:body fat ratio compared with women. ${ }^{21}$ It would therefore be expected that men would have a greater tissue distribution of levofloxacin and subsequent lower serum concentrations than women, as observed in our study. These observations coupled with the differential predictive power of total body weight in men versus women lend strong support for a lean body weight normalization of levofloxacin $\mathrm{V}_{\mathrm{ss}}$ for comparison between the sexes.

Women appear to be more susceptible to fluoroquinolone toxicity than are men, especially in the central nervous system. 3, 6,29 Levofloxacin, however, is a fairly well tolerated fluoroquinolone with a low rate of adverse effects that occur in a concentration-dependent manner. Although increased serum levofloxacin concentrations may result in an increased rate of toxicity in women, fluoroquinolones are concentration-dependent bactericidal agents. Therefore, lower average serum concentrations and decreased levofloxacin exposure in men could result in inadequate antimicrobial activity against bacterial strains moderately susceptible to levofloxacin. This supports the performance of clinical investigations into the efficacy of levofloxacin in men versus women in a large population of patients.

\section{Conclusion}

Compared with men of a similar body mass index, women have a slower $\mathrm{Cl}_{\mathrm{s}}$ and smaller $\mathrm{V}_{\mathrm{ss}}$ of levofloxacin after intravenous administration. These differences lead to a greater drug exposure and higher $\mathrm{C}_{\max }$, respectively, in women. Lean 
body weight had the strongest relationship with both $\mathrm{Cl}_{\mathrm{s}}$ and $\mathrm{V}_{\mathrm{ss}}$ in our study. Nevertheless, after normalization to lean body weight, $\mathrm{V}_{\mathrm{ss}}$ remained significantly smaller in women, suggesting a difference in the pharmacokinetics. Therefore, fixed intravenous doses of levofloxacin will lead to higher $C_{\max }$ in women than in men. This may place women at an increased risk of fluoroquinolone toxicity compared with men but also may necessitate larger doses in men to observe similar antimicrobial efficacy. Therefore, levofloxacin dosage adjustments based on sex or lean body weight should be considered on an individual basis depending on location of infection, susceptibility of the causative microorganism, patient's renal function, and risk for the development of fluoroquinolone toxicity.

\section{References}

1. Geddes AM. Safety of fleroxacin in clinical trials. Am J Med 1993;94:S201-3.

2. Chien SC, Chow AT, Natarajan J, et al. Absence of age and gender effects on the pharmacokinetics of a single 500milligram oral dose of levofloxacin in healthy subjects. Antimicrob Agents Chemother 1997;41:1562-5.

3. Lipsky BA, Baker CA. Fluoroquinolone toxicity profiles: a review focusing on newer agents. Clin Infect Dis 1999;28: 352-64.

4. Shepard CW, Soriano-Gabarro M, Zell ER, et al. Antimicrobial postexposure prophylaxis for anthrax: adverse events and adherence. Emerg Infect Dis 2002;8:1124-32.

5. Sörgel F, Naber KG, Mahr G, et al. Gender related distribution of quinolones. Eur J Clin Microbiol Infect Dis 1990:20-1.

6. Bertino JS Jr, Nafziger AN. Pharmacokinetics of oral fleroxacin in male and premenopausal female volunteers. Antimicrob Agents Chemother 1996;40:789-91.

7. Shah A, Lettieri J, Nix D, Wilton J, Heller AH. Pharmacokinetics of high-dose intravenous ciprofloxacin in young and elderly and in male and female subjects. Antimicrob Agents Chemother 1995;39:1003-6.

8. Efthymiopoulos C, Bramer SL, Maroli A. Effect of age and gender on the pharmacokinetics of grepafloxacin. Clin Pharmacokinet 1997;33(suppl 1):9-17.

9. Overholser BR, Kays MB, Forrest A, Sowinski KM. Sex-related differences in the pharmacokinetics of oral ciprofloxacin. J Clin Pharmacol 2004;44:1012-22.

10. Sowinski KM, Abel SR, Clark WR, Mueller BA. Effect of gender on the pharmacokinetics of ofloxacin. Pharmacotherapy 1999;19:442-6.

11. Hoffler D, Dalhoff A, Gau W, Beermann D, Michl A. Dose- and sex-independent disposition of ciprofloxacin. Eur J Clin Microbiol 1984;3:363-6.

12. Gallicano K, Sahai J. Lack of gender effect on ciprofloxacin pharmacokinetics in humans. Br J Clin Pharmacol 1996;42:632-4.

13. Expert Panel on the Identification, Evaluation, and Treatment of Overweight and Obesity in Adults. Executive summary of the clinical guidelines on the identification, evaluation, and treatment of overweight and obesity in adults. Arch Intern Med 1998;158:1855-67.

14. Devine B. Case study number 25: gentamicin therapy. Drug Intell Clin Pharm 1974;8:650-5.

15. Haycock GB, Schwartz GJ, Wisotsky DH. Geometric method for measuring body surface area: a height-weight formula validated in infants, children, and adults. J Pediatr 1978;93:62-6.

16. Green B, Duffull SB. Development of a dosing strategy for enoxaparin in obese patients. Br J Clin Pharmacol 2003;56:96-103.

17. Liang H, Kays MB, Sowinski KM. Separation of levofloxacin, ciprofloxacin, gatifloxacin, moxifloxacin, trovafloxacin and cinoxacin by high-performance liquid chromatography: application to levofloxacin determination in human plasma. J Chromatogr B Analyt Technol Biomed Life Sci 2002;772:53-63.

18. D'Argenio D, Schumitzky A. ADAPT II user's guide: pharmacokinetic/pharmacodynamic systems analysis software. Los Angeles: University of Southern California, Biomedical Simulations Resource, 1992.

19. Akaike H. An information criterion (AIC). Math Sci 1976;153:5-9.

20. Gibaldi M, Perrier D. Pharmacokinetics. New York: Marcel Dekker, 1982.

21. Schwartz JB. The influence of sex on pharmacokinetics. Clin Pharmacokinet 2003;42:107-21.

22. Yamaguchi H, Yano I, Hashimoto Y, Inui KI. Secretory mechanisms of grepafloxacin and levofloxacin in the human intestinal cell line caco-2. J Pharmacol Exp Ther 2000;295: 360-6.

23. Morris ME, Lee HJ, Predko LM. Gender differences in the membrane transport of endogenous and exogenous compounds. Pharmacol Rev 2003;55:229-40.

24. Chow AT, Fowler C, Williams RR, Morgan N, Kaminski S, Natarajan J. Safety and pharmacokinetics of multiple 750milligram doses of intravenous levofloxacin in healthy volunteers. Antimicrob Agents Chemother 2001;45:2122-5.

25. Hayakawa H, Takagi K, Takano YF, Kawamura Y, Tsuji A. Determinant of the distribution volume at steady state for novel quinolone pazufloxacin in rats. J Pharm Pharmacol 2002;54:1229-36.

26. Cakmakci M, Gossweiler L, Schilling J, Schlumpf R, Geroulanos S. Penetration of fleroxacin into human lung, muscle, and fat tissue. Drugs Exp Clin Res 1992;18:299-302.

27. Mertes PM, Voiriot P, Dopff C, et al. Penetration of ciprofloxacin into heart valves, myocardium, mediastinal fat, and sternal bone marrow in humans. Antimicrob Agents Chemother 1990;34:398-401.

28. Fong IW, Ledbetter WH, Vandenbroucke AC, Simbul M, Rahm V. Ciprofloxacin concentrations in bone and muscle after oral dosing. Antimicrob Agents Chemother 1986;29:405-8.

29. Sawada M, Saishu Y, Hayashi SL. Post-marketing surveillance of levofloxacin in Japan [abstr]. Can J Infect Dis 1995;6(suppl C):385C. 